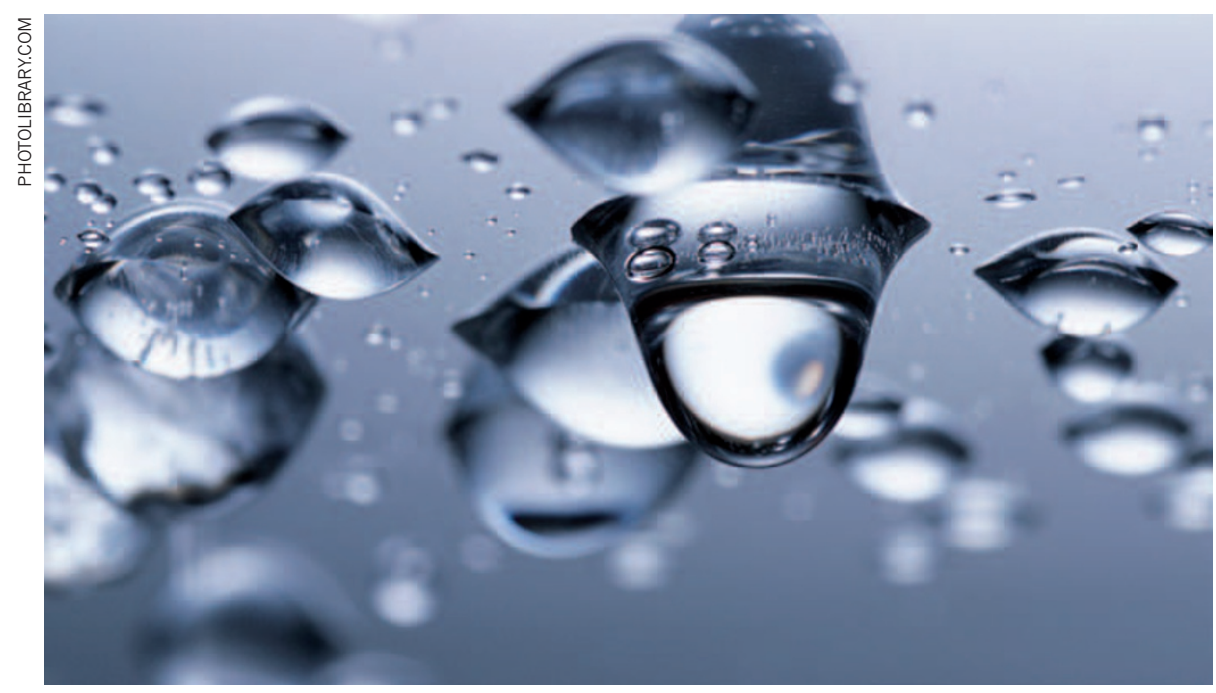

PERSPECTIVE

\title{
Don't foul the water
}

\section{Shifting from corn to perennial crops in making biofuels is essential to save clean water, argues Jeremy Martin.}

\section{$\mathrm{T}$} he most important environmental impacts of biofuels occur not at a car's tailpipe or biorefinery's smokestack, but on the farms that grow the crops to be rendered into liquid transportation fuels. Biofuel production is already at a scale that is reshaping agriculture around the world. In the United States, the production of corn ethanol is polluting surface water and groundwater, while undermining existing efforts to ensure long-term agricultural productivity. Switching to next-generation biofuels made from perennial crops offers the chance to expand biofuel production while protecting water resources and building a more diverse and resilient agricultural system. Yet realizing this potential requires important changes in both biofuel and agricultural policy.

The use of corn grain for ethanol in the United States more than tripled from 2005 to 2010, and more than a third of the US corn crop now goes to ethanol facilities ${ }^{1}$. That trend will continue: the US government mandate for annual biofuel consumption almost entirely corn ethanol - grows from 45 billion litres in 2010 to around 57 billion litres in 2015. This rate of growth far exceeds projected yield increases for corn. And given that demand for food is hardly standing still, the result will be consistently high prices for corn, which will in turn lead to expanded and more intensive corn production.

That could spell trouble for water resources. Although it occupies just 10\% of US farmland (including cropland and pasture), corn consumes $40 \%$ of the fertilizer used in the country. Expansion of corn planting therefore will lead to an even larger leap in the amount of fertilizer applied to the soil, resulting in substantial increases in the amounts of nitrogen and phosphorus infiltrating the ground- and surface waters. Elevated levels of nitrate and pesticides have been found in shallow groundwater in more than half of the United States' agricultural watersheds. Water in more than $20 \%$ of these watersheds exceeds safe drinking water standards for nitrate ${ }^{2}$, which is a potential risk factor for cancer, reproductive problems and methaemoglobinaemia, or 'blue-baby syndrome', which interferes with oxygen transport in the blood of infants.

Most US corn is grown in the Midwestern states. The farm runoff travels down the Mississippi River, ultimately into the Gulf of Mexico, where the influx of excess fertilizer leads to annual algae blooms that deplete the oxygen in the water, killing fish and other marine life. The dead zone that results has over the past five years extended over an area averaging more than 15,000 square kilometres.

Many of the existing programmes to reduce agricultural water pollution were developed in an era of low crop prices, before the expansion of corn ethanol, and rely on incentive payments for voluntary conservation measures. But high crop prices make the incentive payments uncompetitive. High prices also induce farmers to plant corn on erodible and marginally productive land that had previously been set aside for conservation - an agricultural expansion that further degrades water quality, since this land requires more fertilizer and is more susceptible to the loss of fertilizer through leaching or erosion. With corn prices expected to remain high, conservation programmes will continue to lose the bidding war with production.

The shift to second-generation cellulosic biofuels will help to spare water. Perennial crops such as switchgrass (Panicum virgatum), Miscanthus or fast-growing trees require less fertilizer, pesticide and herbicide than corn. Moreover, their deep year-round root systems scavenge fertilizer, so less of it makes its way into the rivers. These roots also sequester carbon (helping to mitigate global climate change) while enhancing long-term soil productivity. Research on Miscanthus and switchgrass at the University of Illinois found that perennial bioenergy crops reduced inorganic nitrogen leaching by more than $90 \%$ compared with a cornsoybean rotation. The study also found that these perennial crops could reduce drainage flows that cause erosion and carry pesticides to surface waters.

The most immediate obstacle to realizing the water quality benefits of perennial bioenergy crops is the absence of a cellulosic biofuel industry. The key challenge facing pioneers in this field is raising capital to build the first commercial-scale biorefineries. Supporting the startup of the first commercial facilities would cost a small fraction of the US $\$ 5$ billion a year the US government now spends on tax credits for corn ethanol.

But investments in energy technology alone will not ensure that biofuels play a constructive role in agriculture. Expanded biofuel production must be accompanied by robust funding and administration of existing agricultural conservation programmes, and smart new policies that target the highest-impact opportunities to protect water resources and the environment even as production expands. Although our ambitions for biofuels may be measured against our oil consumption - and this is as true for biodiesel in the European market as for ethanol in the United States - ultimately the scale at which biofuels can be produced must be constrained by the scarce natural resources upon which we depend for food, fuel and essential environmental services.

Jeremy Martin is a senior scientist at the Cambridge, Massachusetts-based Union of Concerned Scientists.

email:JMartin@ucsusa.org

1. US Department of Agriculture. Feedgrains Yearbook. Updated September. (US Department of Agriculture, 2010).

2. US Environmental Protection Agency. 2008 Report on the Environment. EPA/600/R-07/045F (NTIS PB2008-112484) (US EPA, 2008). 